\title{
Experiments on the wear characteristics of A356 MMNCs fabricated using ultrasonic cavitation
}

\section{Suneel Donthamsetty ${ }^{1}$ and Penugonda Suresh Babu ${ }^{2}$}

${ }^{1}$ Department of Mechanical Engineering, Narasaraopeta Engineering College,

Narasaraopet, Guntur(Dt.), Andhra Pradesh, India, 522601.

Email:ugcnano@gmail.com,nrtec_deanacademics@yahoo.com

Mobile No: 91-9441895535, 91-8647-239918

${ }^{2}$ Department of Mechanical Engineering, Narasaraopeta Engineering College,

Narasaraopet, Guntur(Dt.), Andhra Pradesh, India, 522601.

\begin{abstract}
The wear properties of nanocomposites are evaluated in the present work. Owing to its good castability, A356 has been chosen as matrix material. Since Nano silicon carbide (SiC) and $\mathrm{A} 356$ are close in terms of density, $\mathrm{SiC}$ has been selected as reinforcement material. The dispersion of nano sized reinforcements in the metal matrix composite is challenging due to their higher surface to volume ratio of particles which results in agglomeration and clustering. Hence, the author had proposed an ultrasonic probeassisted stir-casting method in this work for a uniform distribution of particles in the melt. Due to the nano sized reinforcements, interaction at the phase interface becomes enhanced due to the increased surface area which leads to improved material properties, even at a low weight fraction of the reinforcement. So, Nano SiC particles of size 50nm (from 0.1 to 0.5 by wt $\%$ ) were added. Through SEM microstructures, it has been observed that reinforcements were well-dispersed in the aluminium matrix. Test specimens were prepared and tested as per ASTM standard. The experiments were conducted using a pin on the disc wear tester at different loads $(30 \mathrm{~N} \& 40 \mathrm{~N})$ and at constant speed. With the addition of $0.5 \mathrm{wt} \%$ of nanoparticles, the wear resistance of the nanocomposites improved by $53.735 \%$ and $47.04 \%$ at $30 \mathrm{~N}$ and $40 \mathrm{~N}$ respectively compared to pure aluminium alloy.
\end{abstract}

Keywords: Ultrasonic cavitation; SiC; Nanocomposites; wear.

\section{INTRODUCTION}

Nowadays, researchers are focusing more on Nano-composites due to their good properties. These matrices when reinforced with particles, fibres or whiskers (like SiC, $\mathrm{Al}_{2} \mathrm{O}_{3}$ ) assume a dimension of less than $100 \mathrm{~nm}(10-9 \mathrm{~m})$, also called as Metal Matrix Nano-Composites (MMNCs). These MMNCs are promising materials to be used in many fields like automotive, aerospace etc. Due to the small (nano) sized reinforcements, interaction at the phase interface becomes enhanced due to the increased surface area which leads to enhanced materials properties, even at a low volume fraction of the reinforcement. The fundamental issue related to the fabrication of MMNCs is the lack of manufacturing methods that can be used to produce MMNCs in mass amount with a uniform dispersion of nanoparticles. The uniform dispersion of nano particles is imperative to improve the properties of the composite materials. Thus, the author 
proposes an "ultrasonic probe-assisted stir-casting technique" in this work for a better dispersion of nanoparticles [1]. Casting as a liquid stage process is outstanding for its capacity to produce items with complex shapes. It will be alluring to deliver as-cast light weight parts of Metal Matrix Nanocomposites (MMNCs) with great support dissemination and structural integrity. In any case, nano-sized ceramic particles exhibit troublesome issues; it is very hard to scatter them consistently in liquid metals in view of their poor wettability in metal matrices and their huge surface-to volume proportion which effectively incites agglomeration and clustering [2]. With a specific end goal of accomplishing a uniform scattering and dissemination of nanoparticles in aluminum matrix Nanocomposites, Eskin and Eskin [3], Yang et al. [4], Yan et al. [5], Yang and Li [6] built up an imaginative system that joins the hardening forms with ultrasonic cavitation-based scattering of nanoparticles in metal melts. It was accounted for that ultrasonic cavitation can deliver transient (in the order of nanoseconds) micro "hot spots" that can have temperatures of around $5000^{\circ} \mathrm{C}$, pressures over $1000 \mathrm{~atm}$, and heating and cooling rates over $10^{10} \mathrm{~K} / \mathrm{s}$ [7]. Transient cavitations can deliver an implosive effect to separate grouped fine particles and scatter them consistently in liquids. It is imagined that strong smaller scale transient cavitations alongside plainly visible spilling may successfully scatter and appropriate nanoparticles into melts and furthermore improve wettability, in this way making the generation of as-cast elite light weight MMNCs achievable. By using the ultrasonic cavitation-based hardening preparing strategy, A356 alloy strengthened by $\mathrm{SiC}$ nanoparticles hase been manufactured effectively [4, 6, 8-10] and successfully detailed growth in its mechanical properties. In all the above works, the A356 Metal Matrix Nanocomposites (MMNCs) were set up under various trial conditions and process parameters i.e. weight of aluminum dissolve, handling temperature, Nano powder bolstering strategy, time of sonication and so forth.

Liu [11] did a detailed examination on the microstructure and mechanical properties of an $\mathrm{A} 356$ alloy improved with $\mathrm{Al}_{2} \mathrm{O}_{3}$ and $\mathrm{SiC}$ nanoparticles by using the ultrasonic technique. Each type of the nanoparticle was inserted into the A356 molten metal and scattered using ultrasonic cavitation and acoustic streaming technology (UST) to prevent agglomeration or mixing. The outcomes demonstrated that the microstructures were extraordinarily refined and with the addition of nanoparticles, cause an increase in tensile strength, yield strength and elongation. SEM and EDS investigations were also performed to examine the distribution of nanoparticles in the A356 matrix. Since the ultrasonic energy is concentrated in a small region under the ultrasonic probe, it wais hard to ensure proper cavitation and acoustic streaming for the efficient dispersion of the nanoparticles (especially in larger UST systems) without determining the suitable ultrasonic parameters via modelling and simulation. Rana et al. [12] manufactured AA 5083 alloy Micron and Nano $\mathrm{SiC}$ composites using ultrasonic-assisted stir-casting. Different weight $\%$ of Micron $\operatorname{SiC}(3,5,8,10$ wt \%) \& Nano SiC (1, 2, 3 and 4 wt \%) were utilised for the synthesis of composites. Properties like density, elastic modulus, tensile strength, compressive strength, elongation, and hardness for both aluminum alloy micron and nano $\mathrm{SiC}$ composites were measured. The microstructure characterisation of both micron and nano SiC composites were carried out. Results showed that porosity increases with the increase in weight percentage of SiC. Al Nano SiC shows higher values of elastic modulus, tensile strength and compressive strength compared to Al Micron SiC composites. Hardness of composites increases with the increase in weight percentage of $\mathrm{SiC}$. SEM micrograph indicates a uniform dispersion of $\mathrm{SiC}$ particles with some agglomeration in places. The use of ultrasonic vibration on the composite during melting had not only refined the grain microstructure of the matrix, but also enhanced the 
distribution of sub-micron and nano-sized particles. Murthy et al. [13] used the ultrasonicassisted casting-method for the generation of aluminium alloy-based metal matrix reinforced with nanoceramic particles in which the formation of clusters was limited and the nano reinforcements were dispersed consistently in the liquid aluminium metal matrix composite. The ultrasonic-assisted casting-method can control the grain size by minimising the agglomeration of nanoparticles and retaining the enhanced microstructure. This work reviews the properties and morphology of aluminium-based metal matrix nanocomposites fabricated using the ultrasonic-assisted casting process.

Shian Jia [14] manufactured 6061/A356 nanocomposite castings using ultrasonic stirring technology (UST). The 6061/A356 alloy and $\mathrm{Al}_{2} \mathrm{O}_{3} / \mathrm{SiC}$ nanoparticles were utilised as matrix alloy and reinforcement respectively. The applied UST parameters in the experiments were utilised to validate a recently developed multiphase Computational Fluid Dynamics (CFD) model which was utilised to model the nanoparticles' distribution during UST processing. The microstructure, mechanical behaviour and mechanical properties of the nanocomposite castings were examined in detail. The test results revealed that the tensile strength and elongation of the as-cast nanocomposite samples (6061/A356 alloy reinforced by $\mathrm{Al}_{2} \mathrm{O}_{3}$ or $\mathrm{SiC}$ nanoparticles) had improved. The addition of $\mathrm{Al}_{2} \mathrm{O}_{3}$ or $\mathrm{SiC}$ nanoparticles in the 6061/A356 alloy matrix changes the fracture mechanism from being brittle dominated to ductile dominated. A356 is prevalent for casting operations since its silicon content grants it to be extremely fluid while still yielding a high strength value. The high hardness of silicon particles enhances their wear resistance. Thus, the present examination has planned to study A356 Metal Matrix composites by utilising $\mathrm{SiC}$ as the strengthening material in order to study its friction and wear conduct. The wear behaviour of ceramic particle(s) reinforced Aluminum Matrix Composites has been studied by several workers. It includes reinforcements using $\mathrm{SiC}$, $\mathrm{Al}_{2} \mathrm{O}_{3}$, TiC, C, B4C, fly ash, TiB2, Al3Zr etc. either singly or in a hybrid way [15]. In any case, till now work on the wear attributes has not been done using Nano SiC as reinforcement for A356 alloy. The present work aims to bridge this gap. The main objective of the present work includes a successful dispersion of SiC nanoparticles in A356 melt using ultrasonic cavitation-assisted stir casting at different weight percentages, and then establishing the wear characteristics of nanocomposites utilising a pin-on-disc machine at different loads and at constant speed.

\section{METHODS AND MATERIALS}

In this work, A356 [16] is utilised as the network material, and $\mathrm{SiC}$ as the support. The equipment utilised as a part of this work are furnace, ultrasonic probe, frequency generator, temperature controller, inert gas protection nozzles and stirrer. Clarification of the use of these materials and types of equipment will be presented in the sections below.

\section{Materials for experiments}

A356 inferable from promptly castable was chosen as the matrix material. The choice of an appropriate reinforcement relies upon its density, wettability and substance reactivity at high temperatures. Silicon carbide was chosen as the support material in view of its great wettability, about indistinguishable density and the huge contrast of thermal expansion coefficient with aluminum alloys. The A356 that was utilised as part of the present work has $\mathrm{Si}$ as its fundamental alloying component. The composition analysis of the material alongside different properties for example hardness and density are presented in Tables 1 and 2. These estimations were achieved by utilising an optical emission 
spectrometer (Shimadzu-Japan, Model: TDA-7000) and a single pan balance individually at the Chennai Mettex Laboratories, Chennai. SiC nanoparticles integrated using the Chemical Vapour Deposition (CVD) process are utilised as reinforcements in this work. These are described for their virtue and size by utilising XRD examination. X-Ray diffractograms of $\mathrm{SiC}$ nanoparticles with convoluted and deconvoluted charts are shown in Figures 1 and 2. The convoluted chart (Figure 1) indicates numerous characteristic peaks in the checked range with an extreme peak happening at $35.62^{\circ}$. From the deconvoluted chart (Figure 2), the zone under the serious peak is isolated into four separate curves, thus utilising the Gaussian Lorenz curve fitting. For the curves centre of the peak, the Full Width Half Maximum (FWHM) and region under each peak was derived as exhibited in Table 3.

Table 1. Composition Analysis (Wt \%) of A356 Alloy

\begin{tabular}{lccccccccccccc}
\hline $\begin{array}{l}\text { Design } \\
\text { ation }\end{array}$ & $\mathrm{Si}$ & $\mathrm{Cu}$ & $\mathrm{Mn}$ & $\mathrm{Mg}$ & $\mathrm{Zn}$ & $\mathrm{Ti}$ & $\mathrm{Fe}$ & $\mathrm{Ni}$ & $\mathrm{Pb}$ & $\mathrm{Cr}$ & $\mathrm{V}$ & $\mathrm{Co}$ & $\mathrm{Al}$ \\
\hline 356.0 & 6.5 & 0.0 & 0.0 & 0.2 & 0.0 & 0.1 & 0.3 & 0.0 & 0.00 & 0.0 & 0.0 & 0.0 & 92. \\
\hline
\end{tabular}

Table 2. Density \& Hardness of A356 Alloy

\begin{tabular}{ll}
\hline Properties & Value \\
\hline Density (gm/cc) & 2.662 \\
Hardness (Brinell, $10 \mathrm{~mm}$ ball dia \& $500 \mathrm{Kg}$ load) & 57 \\
\hline
\end{tabular}

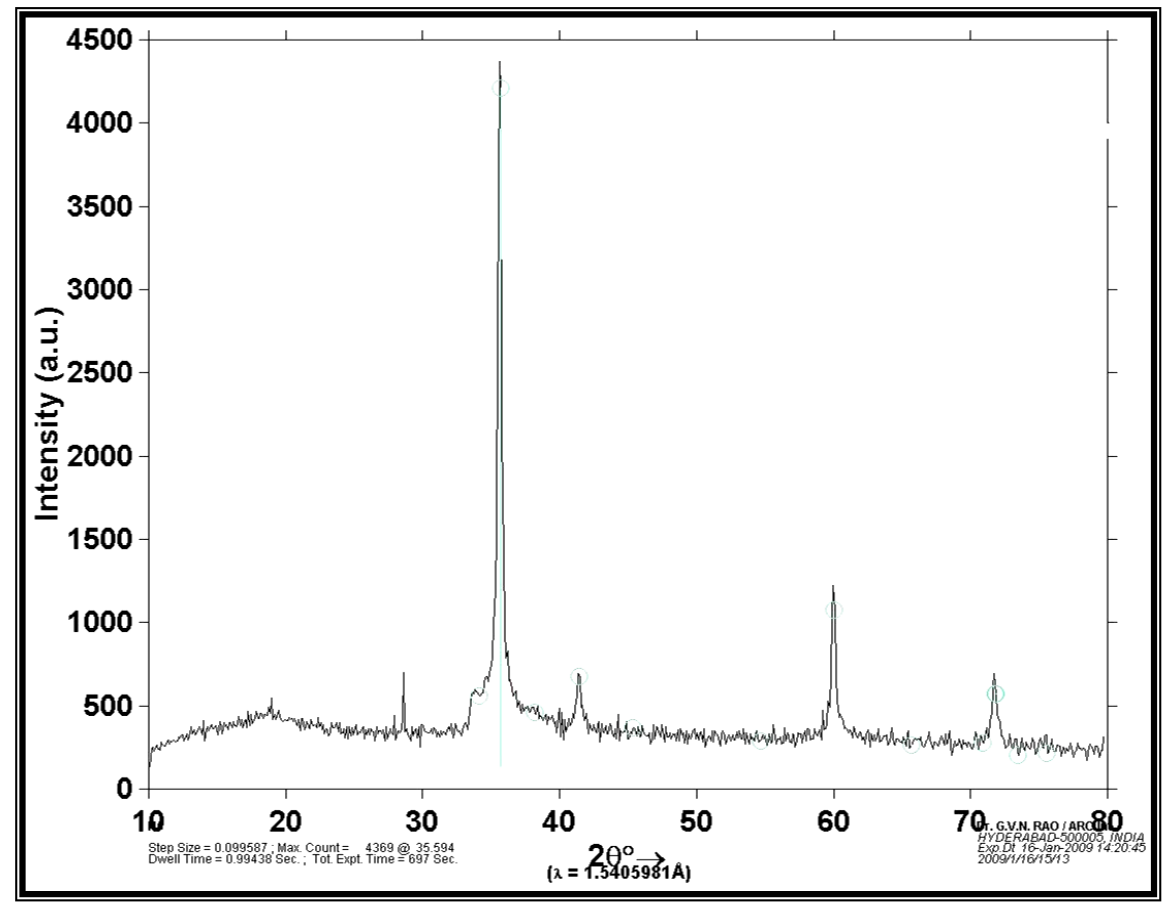

Figure 1. Convoluted graph of intensity profile for SiC nanoparticles. 


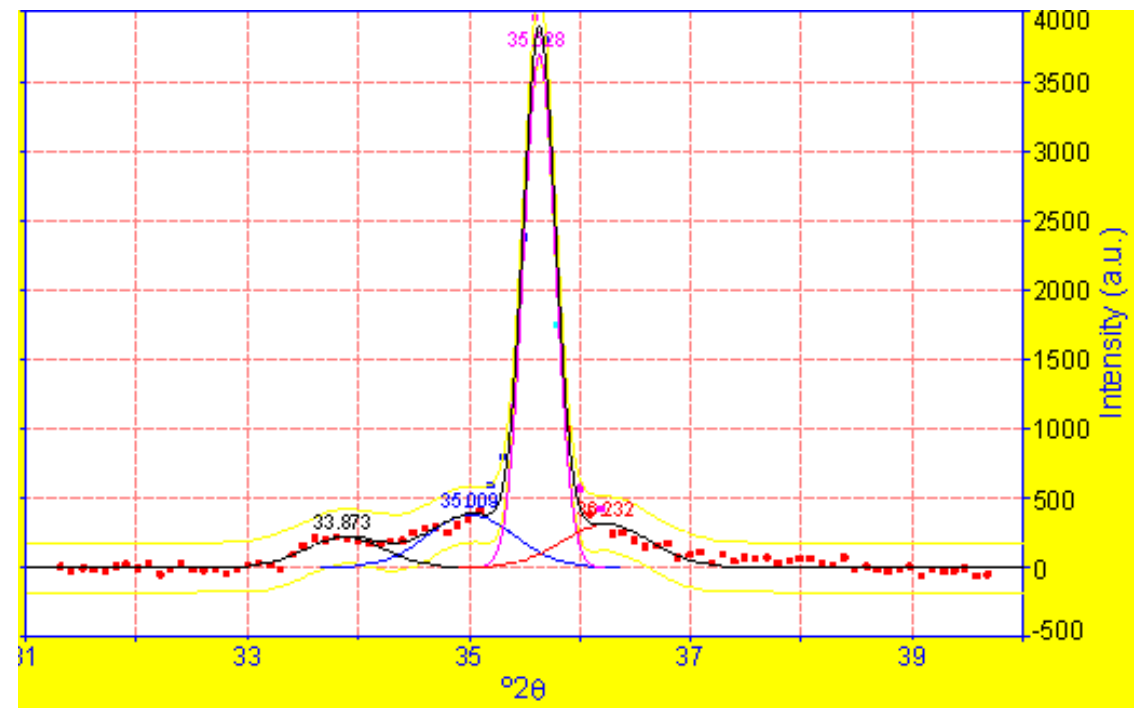

Figure 2. Deconvoluted graph of intensity profile for $\mathrm{SiC}$ nanoparticles.

Table 3. Measured values of characteristic peaks.

\begin{tabular}{ccccc}
\hline Peak & $\begin{array}{c}\text { Peak Angle } \\
(2 \theta \text { in degrees })\end{array}$ & $\begin{array}{c}\text { FWHM } \\
(\text { degrees })\end{array}$ & $\begin{array}{c}\text { \% Area } \\
\text { Under the Peak }\end{array}$ & Crystallite Size, nm \\
\hline 1 & 33.87 & 0.83 & 10.11 & 10.45 \\
2 & 35.00 & 0.91 & 19.47 & 9.15 \\
3 & 35.62 & 0.34 & 70.41 & 24.54 \\
4 & 36.23 & 0.92 & 16.13 & 90.84 \\
\hline
\end{tabular}

The Scherrer formula (Eq.(1)) [17] was used to calculate the average crystallite size from the above tabulated data.

$$
\text { The average crystallite size }(\mathrm{cs})=\frac{K \lambda}{F W H M \times \operatorname{COS} \theta}
$$

where $K=$ Shape factor ( 0.9 for spherical particles); $\lambda=$ Wave length of copper $=$ $1.5405981 \AA$ \& $\theta=$ Diffraction angle for the maximum peak in degrees; $\quad F W H M=$ Full width half maximum of the peak in radians; The XRD results are confirmed by the TEM image (Figure 3) which shows that the nanoparticles are spherical in shape and have an average crystallite size of less than $50 \mathrm{~nm}$ in diameter.

\section{Experimental Set Up}

The nanocomposite manufacturing setup is as shown in Figure 4 and incorporates the furnace, ultrasonic probe, temperature controller, and inert gas protection nozzles. In this procedure, an electric resistance heating unit was utilised to dissolve the A356 in an EN8 steel blend of $110 \mathrm{~mm}$ diameter by $150 \mathrm{~mm}$ height and $1.0 \mathrm{~kg}$ limit. Nanosized $\mathrm{SiC}$ particles were fed to be melted using ultrasonic processing. The aluminum melt pool was secured using argon gas. 


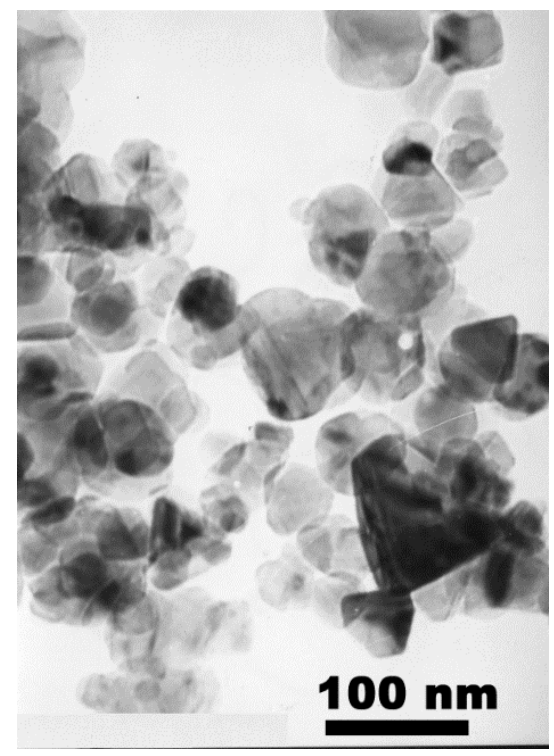

Figure 3. TEM Image of SiC nanopowder.

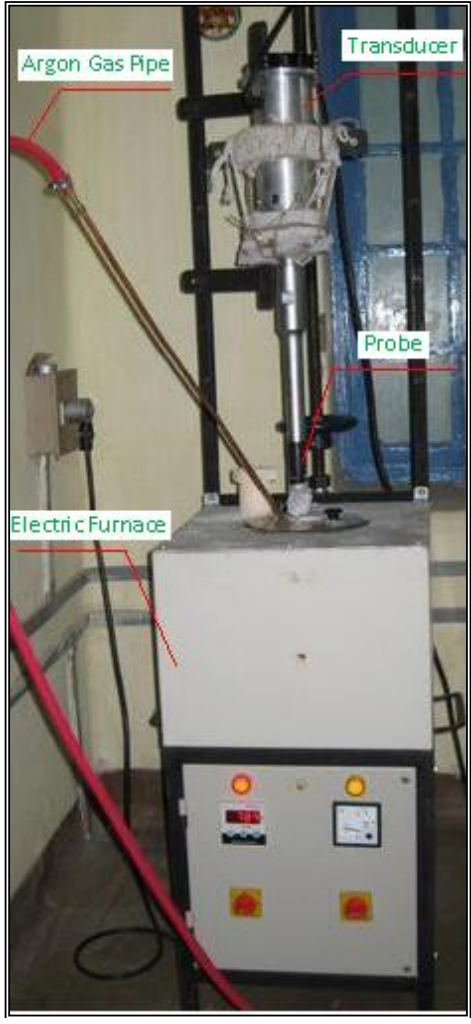

(a)

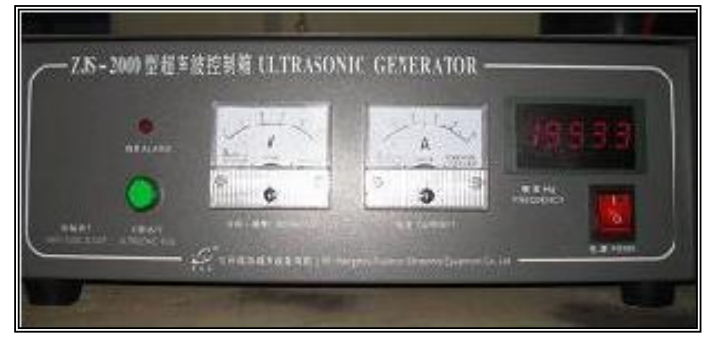

(b)

Figure 4 (a) Electric Furnace with Ultrasonic Transducer (b) Ultrasonic Generator

\section{Production of Metal Matrix Micro- and Nanocomposites}

The handling temperature was controlled at $700^{\circ} \mathrm{C}$, roughly $100^{\circ} \mathrm{C}$ above alloy's melting point $\left(610^{\circ} \mathrm{C}\right)$. An ultrasonic probe (Hangzhou Success Ultrasonic Equipment Co., Ltd, Zhejiang Province, China.) with $20 \mathrm{kHz}, 1 \mathrm{~kW}$ output was utilised to create satisfactory 
processing power inside the crucible. The ultrasonic probe is of $31 \mathrm{~mm}$ diameter and 102 $\mathrm{mm}$ length, and is uncommonly made for aluminum melt which can withstand high processing temperatures with the least ultrasonic cavitation prompted disintegration. An ultrasonic energy of $1 \mathrm{~kW}$ from the transducer was found to create satisfactory non-linear impacts inside the crucible [18]. In spite of the fact that the density of SiC nanoparticles is closer to the density of aluminum 356 alloy, in view of the surface tension of the melt, the nanoparticles tend to coast on the highest point of the dissolved surface at first before ultrasonic cavitation helps to blend them into the melt. So before embedding the probe into the melt, mixing by using a metallurgical stirrer at a speed of $750 \mathrm{rpm}$ for 30 seconds was done. This was a push to moderate higher circumstances of sonication. A356 nanocomposites with different weight rates $(0.1,0.2,0.3,0.4$ and $0.5 \mathrm{wt} . \%)$ of nanosized $\mathrm{SiC}$ were created. The sonication time was 6 minutes for $0.1 \mathrm{wt} \%$, and increased by 6 minutes for each $0.1 \mathrm{wt} \%$ increment. Melts were handled for 30 minutes, most extreme by ultrasonic waves. At the point when the nanosized $\mathrm{SiC}$ particles were included in the Al alloy melts, the viscosity of the liquid $\mathrm{Al}$ alloy essentially expanded. So, after productive ultrasonic preparation, a higher liquid temperature of $750^{\circ} \mathrm{C}$ was utilised to guarantee flowability inside the mould. The high temperature liquid with the fortified nanoparticles was poured into a mild steel mould. After pouring the liquid, it was permitted to cool and set in the shape. The lasting mold for tensile test specimen is as shown in Figure 5(a) softening practice, and the cast specimens for wear are as shown in Figure 5(b-c).

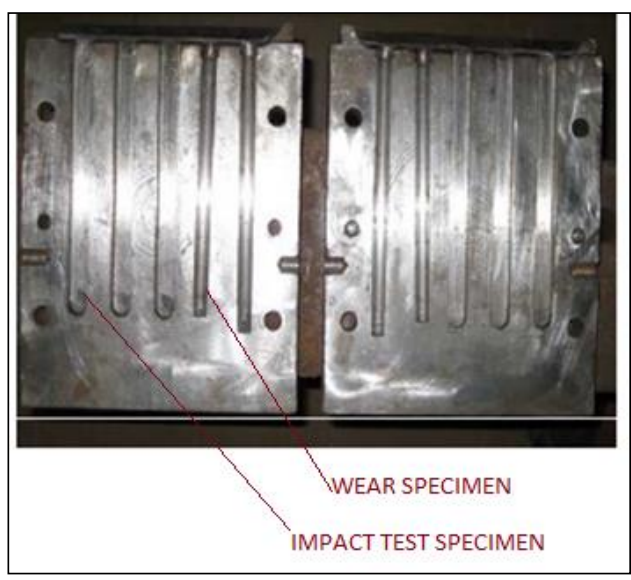

(a)

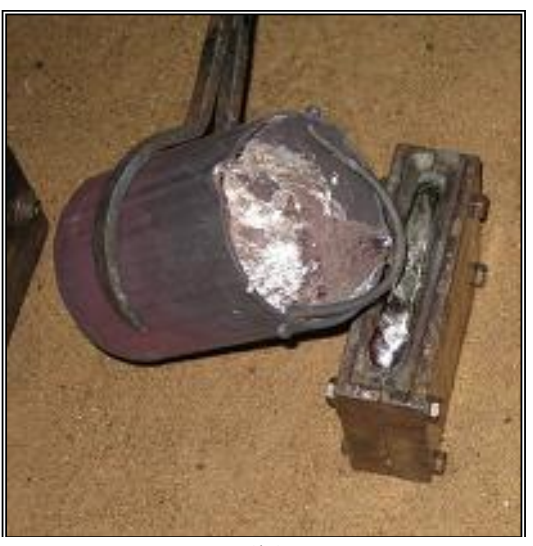

(b)

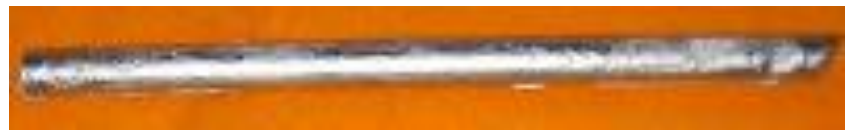

(c)

Figure 5. (a) Permanent mould for wear and impact test of specimen; (b) Pouring molten aluminium into die; (c) Cast specimen for wear test. 


\section{Preparation of Specimen}

To be similar with modern standards, castings were T6 [19] heat-treated. T6 remains the precipitation heat treatment at $155^{\circ} \mathrm{C}$ for 6 hours. Next, the solution was treated at $540^{\circ} \mathrm{C}$ for 5 hours before quenching. For hardness tests, the specimens which are of $8 \mathrm{~mm}$ thickness were metallographically cleaned with a 240 grit $\mathrm{SiC}$ paper until the oxide layer was expelled and the inverse sides were superbly parallel. After that, the disc was polished for better perspective of indentation. For metallographic examination, the specimen wasset up by grinding through 320, 400, 600 and 800 grit papers taken after polishing using $6 \mu \mathrm{m}$ diamond paste and etching by Keller's reagent. The microstructures were investigated using a scanning electron microscope. Specimen (pins) of $50 \mathrm{~mm}$ length and $8 \mathrm{~mm}$ diameter were subjected to the wear test.

\section{RESULTS AND DISCUSSION}

\section{Microstructures}

Samples of the nanocomposites were inspected using SEM, and Figure 6 demonstrates an average SEM picture of the sample with $0.5 \mathrm{wt} \%$ nanosized $\mathrm{SiC}$ particles in the matrix. The nanoparticles were believed to be very much scattered in the A356 grid. Better scattering of nanoparticles is taken as a benchmark for the ideal power limit of the ultrasonic transducer in this work, which is $1 \mathrm{~kW}$.

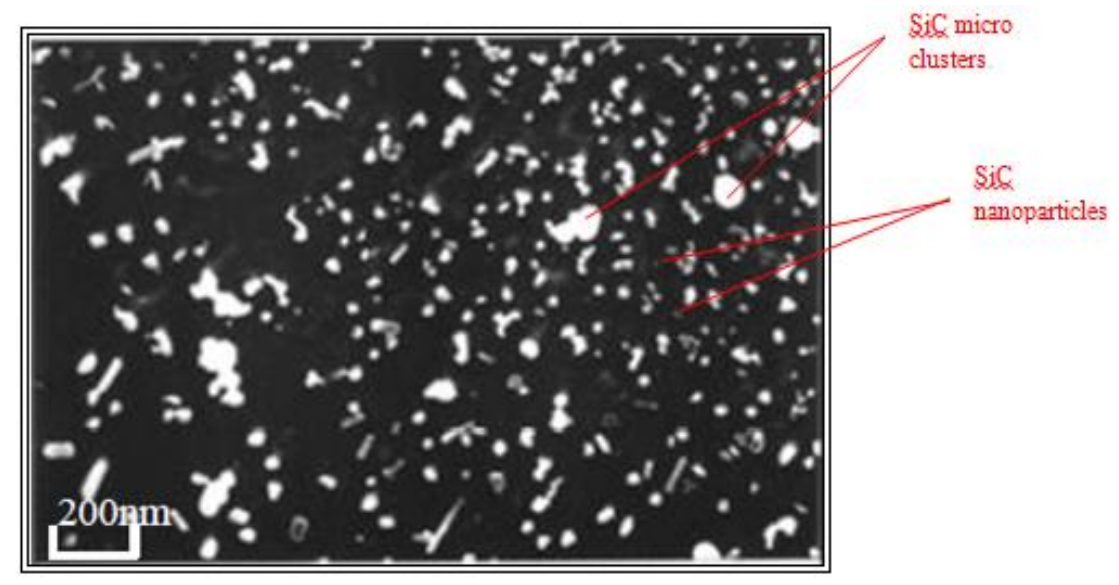

Figure 6. SEM Image of A356 Reinforced with $0.5 \mathrm{wt} \%$ of Nano SiC

\section{Hardness}

The Vickers hardness test has received fairly wide acceptance for research work because it provides a continuous scale of hardness for a given load from very soft metals to extremely hard metals. Hardness tests were carried out to observe the effect of wt $\%$ addition of silicon carbide on the alloy matrix since hardness is an indicator of a material's resistance to plastic deformation. Hardness values corresponding to wt $\%$ are presented in Table 4. Improvement in hardness with $0.5 \mathrm{wt} \%$ reinforced composites was observed to be at $55.55 \%$. 
Table 4. Hardness of nanocomposites.

\begin{tabular}{clc}
\hline Sl. No & \multicolumn{1}{c}{ Specimen } & Hardness $(\mathrm{HV})$ \\
\hline 1 & Pure A356 alloy & 54 \\
2 & A356+0.1Wt\% nano SiC & 59 \\
3 & A356+0.2Wt\% nano SiC & 65 \\
4 & A356+0.3Wt\% nano SiC & 71 \\
5 & A356+0.4Wt\% nano SiC & 77 \\
6 & A356+0.5Wt\% nano SiC & 84 \\
\hline
\end{tabular}

\section{Wear Test}

Unlubricated sliding wear tests were conducted using a pin-on-disc wear tester as per ASTM standards [20]. Tests were conducted at $50 \%$ relative humidity and a temperature of $28{ }^{\circ} \mathrm{C}$. The specimens under tests were fixed to the holder against EN32 (hardness of $500 \mathrm{HV}$ ) steel disc. The specimen holder along with the specimen (Pin) was positioned at the track diameter of $100 \mathrm{~mm}$. Load was applied by placing dead weights on the loading pan, and transferred to the specimen through the cantilever mechanism while the specimen remain fixed and the disc rotated at $800 \mathrm{~min}^{-1}(4.187 \mathrm{~m} / \mathrm{sec})$. The speed of the disc or motor $\min ^{-1}$ can be varied using the controller. The pin-on-disc apparatus and its loading panel are shown in Figure 7.

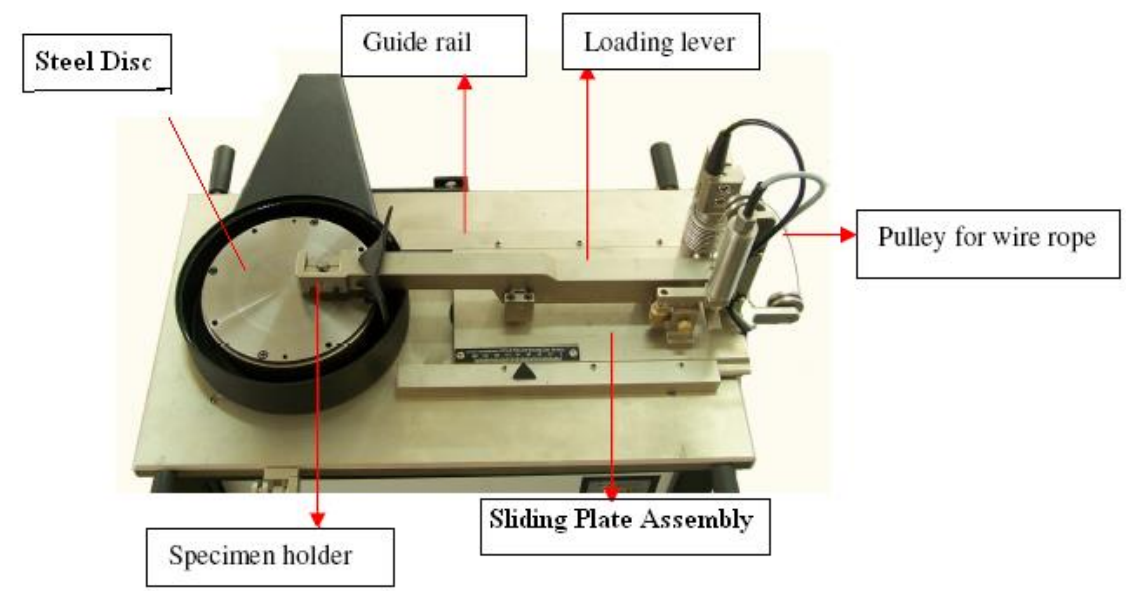

(a)

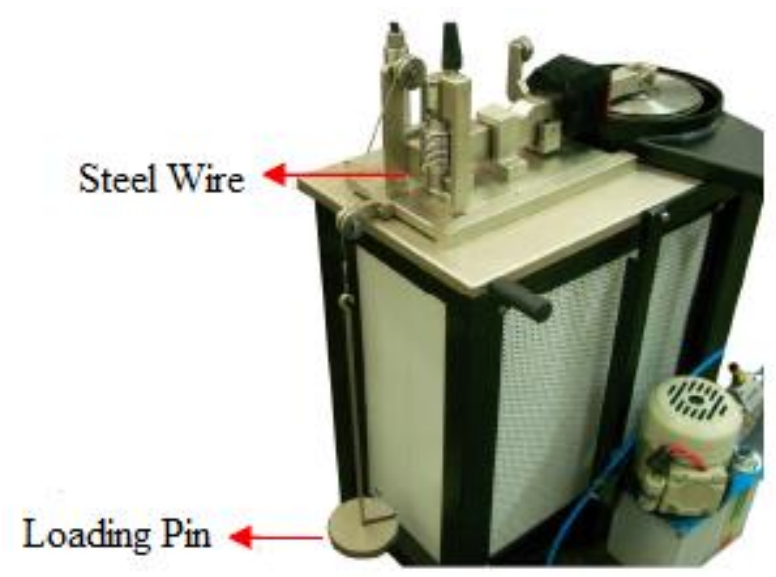

Figure 7. (a) Pin on disc and sliding plate assembly; (b) Loading panel. 
The surfaces of the pin sample and the steel disc were grounded using emery paper prior to each test. Specimens (pins) of length $50 \mathrm{~mm}$ and diameter $8 \mathrm{~mm}$ were subjected to wear tests up to a sliding distance of $2000 \mathrm{~m}$ under varying applied pressures of $0.6 \&$ $0.8 \mathrm{MPa}$ (loads of $30 \mathrm{~N} \& 40 \mathrm{~N}$ ). For each composite, three specimens were tested under the same conditions. Care has been taken to ensure that the specimens under test were continuously cleaned with a woollen cloth to avoid the entrapment of wear debris. The test pieces were cleaned with acetone before and after each test. Tangential frictional force and wear were monitored using electronic sensors and recorded on a Personal Computer. The automotive industry has successfully applied Al-based micro particulate composites, chiefly $\mathrm{SiC} / \mathrm{Al}$ and $\mathrm{Al} / \mathrm{Al}_{2} \mathrm{O}_{3}$, in pistons, engine blocks, disc rotor brakes, drums, callipers, connecting rods, internal combustion engine cylinder liners and other parts. The metal matrix composite displayed lower wear rate, and the abrasive wear rates were reduced by $55-90 \%$ compared to $\mathrm{Al}$ alloys by adding approximately $20 \mathrm{vol}$. \% of micro SiC particles [21]. Hence, wear tests were conducted on the fabricated nanocomposites using the pinon-disc apparatus. Figure 8 shows the variation of wear volume with sliding distance of the specimen for different loads $(30 \mathrm{~N}, 40 \mathrm{~N})$ at $800 \mathrm{~min}^{-1}$. It isseen from the plots that with an increase in the \% of nanoparticles, the wear volume of the composite had decreased. It is also observed that the wear volume increased as the sliding distance was increased for the entire test period. It is evident from the plot that for any weight fraction of nanoparticles, the wear of composite at any point of sliding distance and load is lower than pure aluminum alloy. This indicates the influence of the percentage of reinforced nanoparticles on the wear behaviour. A notable increase in wear resistance by $53.735 \%$ at $30 \mathrm{~N}$ and $47.04 \%$ at $40 \mathrm{~N}$ was obtained with $0.5 \mathrm{wt} \%$ nanoparticles. Wear volumes, coefficient of friction, and frictional force for all specimens at the end of the test i.e. at $2000 \mathrm{~m}$ are presented in Table 5. It is seen from the plots (Figure 8) that volumetric wear increased with an increase in normal load. This may be attributed to the increase in frictional thrust at higher loads, causing debonding and fracture (Figure 9). The coefficient of friction and frictional force of the alloy and nanocomposites were recorded at different applied loads and tabulated in Table 5. Composites showed the lowest coefficient of friction compared to pure alloy, as the dispersion of $\mathrm{SiC}$ particles reduces the coefficient of friction. Hence, a low coefficient of friction indicates that $\mathrm{SiC}$ particles are well-dispersed in the composite.

Table 5. Coefficient of friction and tangential frictional force for nanocomposites.

\begin{tabular}{clcccccc}
\hline & & \multicolumn{3}{c}{ Normal Load=30N } & \multicolumn{3}{c}{ Normal Load=40N } \\
\cline { 3 - 8 } S1.No & Specimen & $\begin{array}{c}\text { Wear } \\
\text { Volume } \\
\left(\mathrm{mm}^{3}\right)\end{array}$ & $\begin{array}{c}\text { Frictional } \\
\text { Force, } \mathrm{F} \\
(\mathrm{N})\end{array}$ & $\begin{array}{c}\text { Coefficient } \\
\text { of Friction }\end{array}$ & $\begin{array}{c}\text { Wear } \\
\text { Volume } \\
\left(\mathrm{mm}^{3}\right)\end{array}$ & $\begin{array}{c}\text { Frictional } \\
\text { Force, F } \\
(\mathrm{N})\end{array}$ & $\begin{array}{c}\text { Coefficient } \\
\text { of Friction }\end{array}$ \\
\hline 1 & Pure A356 alloy & 10.961 & 8.8 & 0.29 & 15.47 & 15.1 & 0.38 \\
2 & $\begin{array}{l}\text { A356+0.1Wt\% } \\
\text { nano } \mathrm{SiC}\end{array}$ & 9.252 & 8.6 & 0.28 & 13.46 & 14.4 & 0.36 \\
3 & $\begin{array}{l}\text { A356+0.2Wt\% } \\
\text { nano } \mathrm{SiC}\end{array}$ & 7.698 & 7.9 & 0.26 & 11.72 & 11.5 & 0.28 \\
4 & $\begin{array}{l}\text { A356+0.3Wt\% } \\
\text { nano } \mathrm{SiC}\end{array}$ & 6.882 & 7.4 & 0.24 & 10.10 & 10.8 & 0.27 \\
5 & $\begin{array}{l}\text { A356+0.4Wt\% } \\
\text { nano } \mathrm{SiC}\end{array}$ & 6.350 & 5.8 & 0.19 & 9.23 & 10.5 & 0.26 \\
6 & $\begin{array}{l}\text { A356+0.5Wt\% } \\
\text { nano } \mathrm{SiC}\end{array}$ & 5.071 & 5.5 & 0.18 & 8.19 & 9.6 & 0.24 \\
\end{tabular}




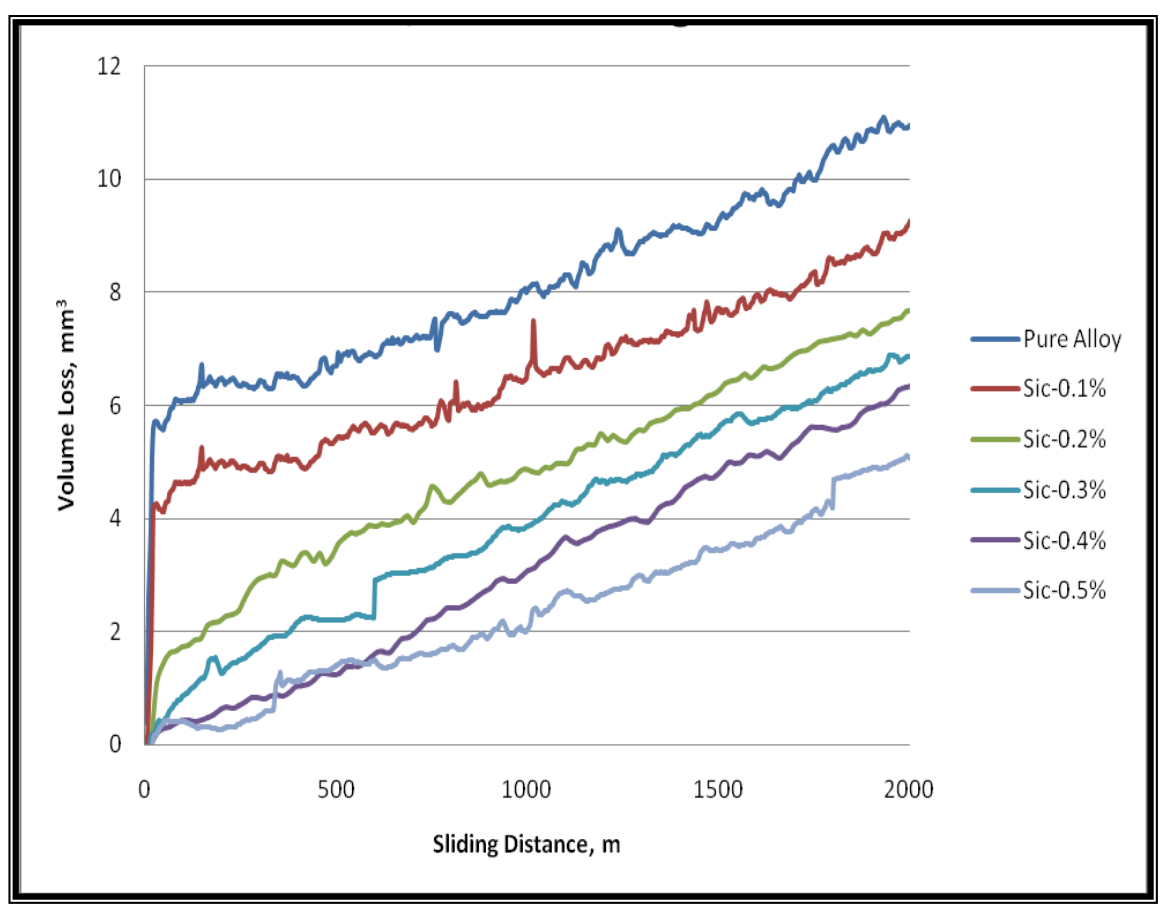

(a) $30 \mathrm{~N}$

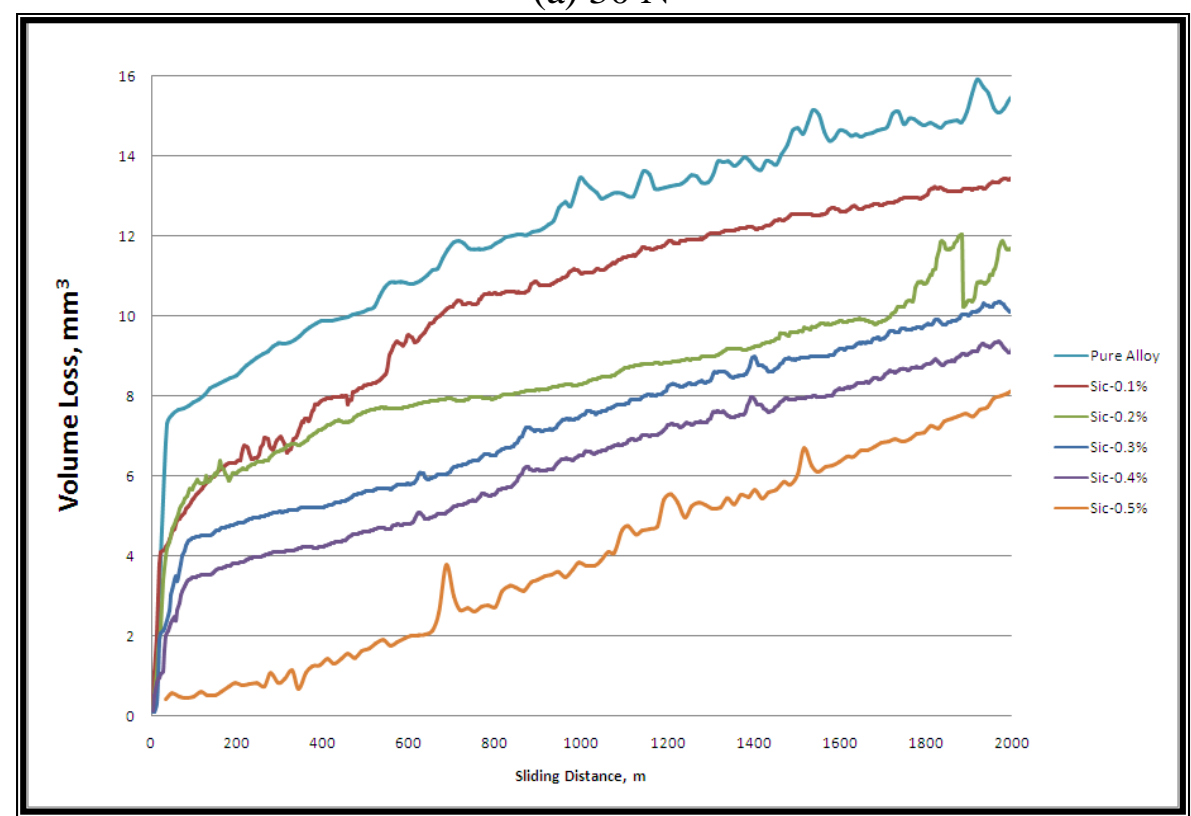

(b) $40 \mathrm{~N}$

Figure 8 Volume loss against sliding distance at a normal load.

To understand the wear pattern of aluminum alloy and its composite, the wornout surface of some selected typical specimens after the wear test were observed under SEM. Wear surfaces due to micro-cutting show deep narrow grooves for pure alloy and shallow wide grooves for $0.5 \mathrm{wt} \%$ composite (Figure 9). The variation in the formation of wide grooves on the surface may be due to an increase in the hardness of the composite compared to pure alloy (Table 4) White spots in Figure 9 shows the wear debris detached from the wear surface. 


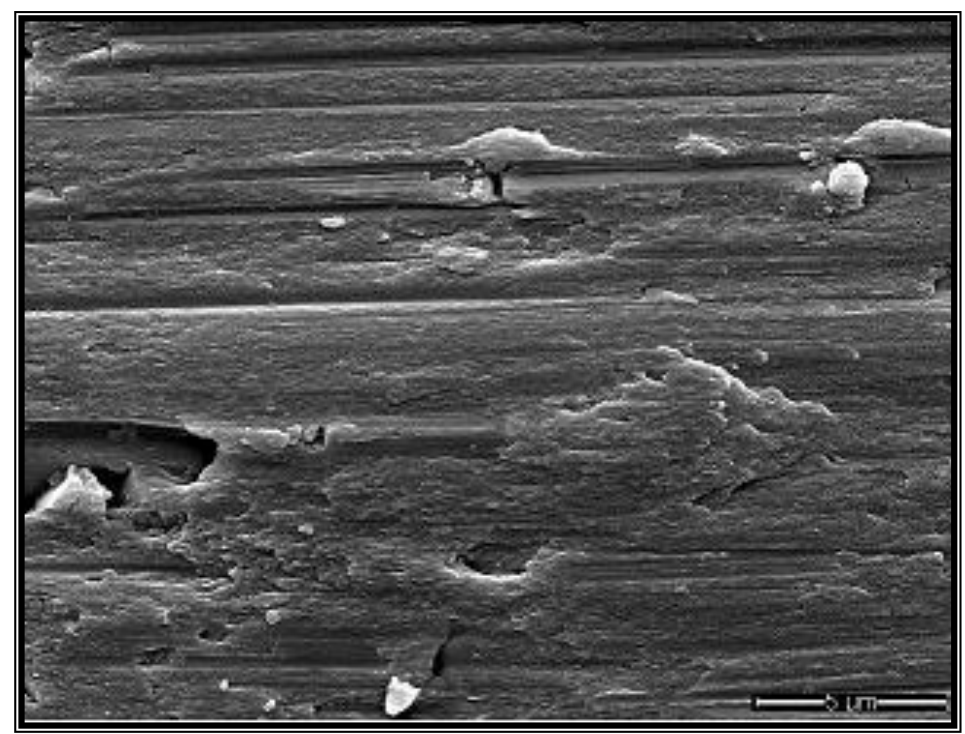

(a)

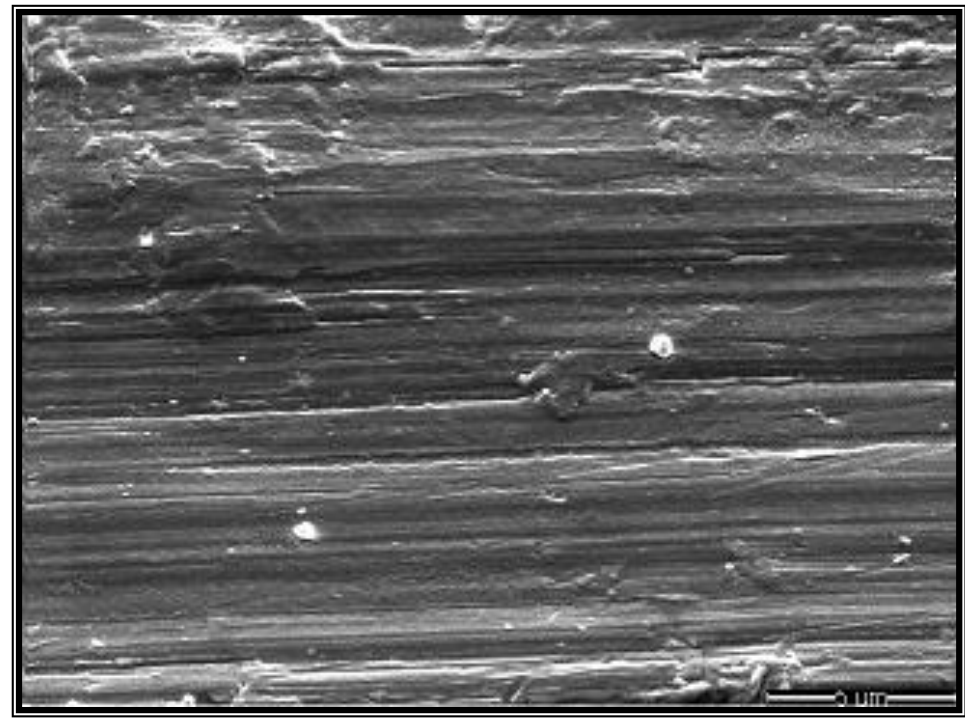

(b)

Figure 9 (a). SEM Image for worn surface of pure alloy under 40N load; (b) SEM image for worn surface of $0.5 \mathrm{wt} \%$ nanocomposite under $40 \mathrm{~N}$ load.

\section{CONCLUSIONS}

In this study, the wear characteristics of $\mathrm{A} 356$ reinforced with $\mathrm{SiC}$ nanoparticles were examined, and it was found that at $0.5 \mathrm{wt} \%$ nanoparticles, the wear resistance improved by $53.735 \%$ and $47.04 \%$ at $30 \mathrm{~N}, 40 \mathrm{~N}$ respectively compared to pure aluminium alloy. It was also witnessed that the formation of wide grooves over composite surfaces was due to the increase in hardness with the weight percentage of nanoparticles and deep and narrow grooves on the pure alloy. Present work can be further extended to different particle sizes, weight percentages and other materials to study the effect of the particles on the properties of the composite. Since this is a new area, properties like fatigue strength, thermal conductivity, weldability, and high temperature mechanical properties etc. may also be established. The present work was done at a laboratory scale, thus scaling 
up to the industry level needs design and constructional modification of the ultrasonic transducer.

\section{ACKNOWLEDGEMENTS}

The authors would like to be obliged to University Grants Commission-New Delhi for sanctioning grant of 10.36 Lakhs as a financial assistance under Major Research Project. Project Ref. No. 33-401/2007 (SR) dated 28-2-2008.

\section{REFERENCES}

[1] Muley AV. Ultrasonic probe assisted stir casting method for metal matrix nanocomposite manufacturing : an innovative method. International Journal of Mechanical And Production Engineering. 2015;3:111-3.

[2] Suneel D, Rao DN. Scope of ultrasonic cavitation in the fabrication of metal matrix nanocomposites (an analytical cum simulation approach). 2nd International \& 23rd All India Manufacturing Technology, Design and Research Conference, 15-17 December. Indian Institute of Technology Madras, India; 2008.

[3] Eskin GI, Eskin DG. Production of natural and synthesized aluminum-based composite materials with the aid of ultrasonic (cavitation) treatment of the melt. Ultrasonics sonochemistry. 2003;10:297-301.

[4] Yang Y, Lan J, Li X. Study on bulk aluminum matrix nano-composite fabricated by ultrasonic dispersion of nano-sized $\mathrm{SiC}$ particles in molten aluminum alloy. Materials Science and Engineering: A. 2004;380:378-83.

[5] Yan J, Xu Z, Shi L, Ma X, Yang S. Ultrasonic assisted fabrication of particle reinforced bonds joining aluminum metal matrix composites. Materials \& Design. 2011;32:343-7.

[6] Yang Y, Li X. Ultrasonic cavitation-based nanomanufacturing of bulk aluminum matrix nanocomposites. ASME Journal of Manufacturing Science and Engineering. 2007;129:252-5.

[7] Rehorek D. Ultrasound Its Chemical, Physical, and Biological Effects WileyVCH Verlag GmbH \& Co. KGaA; 1989.

[8] Cao G, Konishi H, Li X. Mechanical properties and microstructure of SiCreinforced $\mathrm{Mg}-(2,4) \mathrm{Al}-1 \mathrm{Si}$ nanocomposites fabricated by ultrasonic cavitation based solidification processing. Materials Science and Engineering: A. 2008;486:357-62.

[9] Cao G, Choi H, Konishi H, Kou S, Lakes R, Li X. Mg-6Zn/1.5\%SiC nanocomposites fabricated by ultrasonic cavitation-based solidification processing. Journal of Materials Science. 2008;43:5521.

[10] D.Suneel. Investigations on mechanical properties of A356 nano composites reinforced with high energy ball milled sic nanoparticles (with a comparison of micro composite). In International Journal of Nanoparticles. 2013;6:38-49.

[11] Liu X. Fundamental studies on ultrasonic cavitation-assisted molten metal processing of a356-nanocomposites 2013.

[12] Rana RS, Purohit R, Soni S, Das. S. Comparison of Mechanical Properties and Microstructure of Aluminum alloy Micron and Nano SiC Composites fabricated by Ultrasonic Vibration. International Journal of Advance Engineering and Research Development. 2014;1:135-46. 
[13] Murthy NV, Reddy AP, Selvaraj N, P.Rao CS. Review on fabrication of aluminium alloy based metal matrix nano composites through ultrasonic assisted casting. Journal of Metallurgical and Materials Engineering Research. 2015;1:18.

[14] Shian Jia LN. Experimental and theoretical analyses on the ultrasonic cavitation processing of al-based alloys And nanocomposites 2015.

[15] Unidentified. Chapter 2 - Literature Review: http://shodhganga.inflibnet.ac.in/bitstream/10603/57371/9/09_chapter\%202.pdf; Unidentified.

[16] Kaufman JG, Rooy EL. Aluminum Alloy Castings Properties, Processes, and Applications ASM International; 2004.

[17] B.D.Cullity. Elements of X-ray diffraction. London: Addison Wesley Publishing Co.Inc,; 1962.

[18] D.Suneel, Rao DN. Estimation of cavitation pressure to disperse nano reinforcements in metal matrix nano composites. International Journal of Nanosystems, Electrical and Electronics Engineering. 2008;1:57-63.

[19] ASTM. B917, Standard Practice for Heat Treatment of Aluminum- Alloy Castings from all Processes.: ASTM International; 2012.

[20] ASTM. G99-05, Standard Test Method for Wear Testing with a Pin-on-Disk Apparatus. ASTM International; 2005.

[21] D. W. State-of-the-Art in Cast MMC's in the next millennium. . In: TMS PR, Warrendale P, editors. 2001. p. 259. 